\title{
SYEKH AHMAD KHATIB AL-MINANGKABAWI; ICON THOLABUL ILMI MINANGKABAU MASA LALU UNTUK REFLEKSI SUMATERA BARAT HARI INI DAN MASA DEPAN
}

\author{
Eka Putra Wirman \\ UIN Imam Bonjol Padang \\ ekaputrawirman@uinib.ac.id
}

\begin{abstract}
Abstrak. Syekh Ahmad Khatib Al-Minangkabawi. Salah satu tokoh Minangkabau yang menonjol di bidang keislaman adalah Syeikh Ahmad Khatib al-Minangkabawi. Selain sebagai ulama kaliber internasional, beliau juga telah melahirkan murid-murid yang kemudian menjadi ulama dan tokoh penting pergerakan Islam dan sosial di Asia Tenggara. Dua organisasi sosialkeagamaan yang terbesar di Indonesia yaitu Muhammadiyah dan Nahdlatul Ulama didirikan oleh murid-murid Syeikh Ahmad Khatib. Ulama besar ini dikenal pula dengan semangat berdiskusi secara objektif dengan orang-orang yang tidak satu pemahaman dengan beliau tanpa terganggunya hubungan silaturrahim antara mereka. Keberadaan tokoh besar yang lahir di Minangkabau ini boleh jadi menghilang sedikit demi sedikit dari memori umat Islam, oleh karena itu perlu dilakukan eksplorasi terus menerus terhadap perjalanan hidup, perjuangan dan karya ilmiah yang telah dilakukan. Tulisan ini merupakan salah satu upaya untuk menjaga, melestarikan dan mengembangkan pemikiran dan karya a Sheikh Ahmad Khatib al-Minangkabawi.
\end{abstract}

Kata Kunci: Thalabul Ilmi, al-Haram, al-Azhar, Pembaruan.

\begin{abstract}
Syekh Ahmad Khatib Al-Minangkabawi. One of important Minangkabau Islamic syeikhs is Ahmad Khatib al-Minangkabawi. He is not only as international syeikh, but also he has educated many students who become important figures of Islamic and social studies in Southeast Asia. Indeed, there are two important Islamic organizations; Muhammadiyah and Nahdatul Ulama which have been established by his followers. He has also become welknown figure who liked to discuss some religion issues with others objectively. It is assumed that majority of contemporary Muslims in Minangkabau do not know him well. Thus, the objective of this paper to explore on Ahmad Khatib al-Minangkabawi' biography, struggle, and publications. This writing aims at keeping, rejuvenating, developing his ideas and works.
\end{abstract}

Keywords: Thalabul Ilmi, al-Haram, al-Azhar, Reformation.

\section{PENDAHULUAN}

Minangkabau memiliki "harta karun" yang tidak habis untuk dikaji. Harta karun itu berupa ide dan gagasan anak nagari yang telah mampu menyempurnakan kompe-tensi dirinya dengan segala kete-kunan, keuletan dan cara berpikir yang rasional.
Minangkabau tidak termasuk daerah dengan peninggalan purba yang adiluhung seperti pada etnis lainnya di Indonesia. Tambo alam Minangkabau yang merupakan warisan berharga dari generasi terdahulu, belum mampu mempo-sisikan diri disejajarkan dari 
segi orisinalitas, otentisitas dan otoritasnya dibanding kisah-kisah sastra dari budaya lain. Kisah wayang umpamanya, telah melegenda dan memiliki nomenklatur dan pakem tersendiri. Bandingkan dengan kisah dan legenda yang ada di Minang-kabau yang belum mampu keluar dari mitos menuju realitas meskipun berasal dari legenda juga.

Warisan yang bisa diangkat dan sebagian masih terpendam adalah konsep dan gagasan anak nagari dari berbagai aspek kehi-dupan. Pembicaraan tentang konsep negara Indonesia pasti tidak akan lepas dari putra-putri Minangkabau. Apabila ada pembicaraan tentang tokoh nasional yang telah meletakkan dasar-dasar filosofis negara Indonesia, maka tidak kurang dari setengah dari lima nama adalah anak nagari Minangkabau. Dalam bidang keilmuan Islam, terutama pada masa awal kemerdekaan Islam, dari sekian ulama berpengarauh pasti muncul sederet ulama berkualitas dari anak nagari Minangkabau. Begitu pula dalam bidang sastera dan jurnalistik, banyak bermunculan anak nagari Minangkabau yang menjadi tokoh nasional.

Harta yang berharga ini perlu dijaga dan sekaligus digali agar dapat memberikan inspirasi bagi generasi berikut. Di samping itu menggali karya tokoh-tokoh terdahulu dapat memberikan konstribusi agar tokoh tersebut ditempatkan pada posisi yang semestinya. Karena itu, melakukan kajian-kajian secara intens terhadap sejarah bangsa, termasuk peran para tokoh bangsa, menjadi penting dan mendasar. Terlebih lagi terhadap tokoh-tokoh yang cenderung belum tereksplorasi selama ini, meski nama besarnya tersohor melebihi tokohtokoh lain yang telah banyak dicatat sejarah.

Sejarah bukan sekedar romantisme masa lalu, tetapi esensinya adalah untuk bekal masa depan. Sejarah memberi kontribusi positif bagi generasi penerus bangsa dengan menjadikannya teladan. Lebih dari itu, semangat dan nilai juang pelaku sejarah bisa diadopsi untuk menghadapi berbagai persoalan kekinian.

Menggali khazanah warisan ulama-ulama besar menjadi lebih penting dalam konteks Sumatera Barat. Realitas sosio historis dan kulturalnya tak terpisahkan dari peran ulama, karena dinamika Sumatera Barat adalah dinamika Minangkabau yang memiliki filosofi Adat Basandi Syarak-Syarak Basandi Kitabullah (ABS-SBK). Disini, peran ulama sangat signifikan dan sama sekali tidak bisa dimarjinalkan. Pada sisi lain, disadari atau tidak, ternyata masih banyak khazanah ulama yang masih terpendam. Mutiara sejarah yang sangat berharga itu belum tergali secara maksimal, sehingga nilai-nilainya nyaris belum ter-transformasikan pada generasi penerus. Karena itu, menggali untuk kemudian memanfaatkannya menjadi tugas mendasar kita generasi hari ini.

Salah satu warisan anak nagari di Minangkabau adalah seorang pribadi yang memiliki reputasi internasional di dunia Islam. Pribadi yang akan dikaji dalam momen ini adalah Syeikh Ahmad Khatib al-Minangkabawi. Seorang ulama penting dari Nusantara, yang menjadi pumpunan para penuntut ilmu dari berbagai negeri berbagai 
mazhab dan berbagai kecenderungan keagamaan. Tidak berlebihan dan tampaknya terbukti, jika Agus Salim, tokoh bangsa yang sekaligus kerabat dan murid Ahmad Khatib menyebut bahwa belum tentu dalam waktu seratus tahun akan lahir tokoh sebesar Ahmad Khatib (Dandang A. Dahlan, 2003:1).

Makalah ini akan menfo-kuskan diri untuk memotret salah satu aspek dari kehidupan Syeikh Ahmad Khatib yaitu yang berkaitan dengan semangat keilmuan dan gemanya di masa sekarang. Lebih dari itu untuk mentrans-formasikan semangat tholabul ilmi yang tinggi, sambil membangun tradisi polemik, berdiskusi dengan perbedaan pendapat dalam keilmuan yang dibingkai oleh semangat ilmiah akademis penuh persaudaraan, yang telah diartikulasikan dengan baik oleh Syeikh Ahmad Khatib alMinangkabawi kepada murid-muridnya para ulama terdepan Minangkabau. Diharapkan ke depan, semangat menuntut ilmu yang tinggi kembali diwarisi generasi Sumatera Barat.

\section{RIWAYAT HIDUP RINGKAS SYEIKH AHMAD KHATIB}

\section{Asal Usul}

Ulama besar ini nama lengkapnya adalah Ahmad Khatib bin Abdul Latif bin Abdurrahman bin Abdullah bin Abdul Aziz Al Khathib Al Jawi Al Makki Asy Syafi'i alMinangkabawi. Lahir pada hari Senin tanggal 6 Dzulhijjah 1276 H/1860M. di Koto Tuo Balai Gurah Kecamatan IV Angkek Candung Bukittinggi pada tahun $1276 \mathrm{H} / 1860 \mathrm{M}$. Beliau wafat di Makkah hari Senin 8 Jumadil Awal 1334 H/1916 M) setelah berkiprah selama kurang lebih 56 tahun.
Ayahnya adalah Buya Abdul Latif yang merupakan seorang ulama mumpuni di zamannya. Sementara ibunya bernama Limbak Urai asal Koto Tuo Balai Gurah. Ahmad Khatib Memiliki 5 saudara yaitu H. Mahmud, H. Aisyah, H. Hafsah, H. Safiah. Dari pihak bapak, beliau memiliki hubungan dengan H. Agus Salim, sedangkan dari pihak ibu beliau bersaudara ibu dengan H. Thaher Jalaluddin seorang ulama falak yang menentap dan meninggal di Malaysia. Melihat silsilahnya, Sheikh Ahmad Khatib memiliki hubungan dengan Tuanku Nan Tuo seorang guru dari para pejuang dan ulama-ulama Paderi. (ICSB: 15).

Beliau menikah dengan Khadijah putri dari Muhammad Saleh Kurdi seorang pemilik toko buku di Makkah. Shaleh al-Kurdi sangat tertarik dengan Ahmad Khatib sehingga mengangkatnya sebagai menantu. Tidak beberapa lama Khadijah meninggal dunia dengan meninggalkan seorang anak bernama Abdul Karim. Shaleh al-Kurdi begitu simpati dengan Ahmad Khatib terutama karena kerajinan, ketekunan, kepandaian dan penguasaannya terhadap ilmu agama serta keshalihannya. Maka Shaleh al-Kurdipun menikahkan Ahmad Khatib dengan anak keduanya Fatimah dan memberinya tiga orang anak yaitu Abdul Malik, Abdul Hamid dan Khadijah.

\section{Pendidikan}

Ahmad Khatib mengenyam pendidikan formal dari pendidikan dasar sampai ke Sekolah Raja atau Kweekschool tahun 1871 M. Pengetahuan agama termasuk menghafal alQuran diperoleh melalui ayahnya Syeikh Abdul Lathif. Pada tahun 1287 
H Abdul Latif berangkat ke Makkah untuk menunaikan ibadah haji. Selain orang tuanya, ikut dalam rombongan itu kakeknya Syeikh Abdullah dan pamannya Abdul Ghani yang merupakan orang terkaya di kampung halamannya. bersama Setelah melaksanakan ibadah haji Ahmad Khatib tidak ikut serta dengan orang tuanya kembali ke Sumatera Barat dan tetap tinggal di Makkah dengan maksud menuntut ilmu agama dan hafalan Al Quran dari para ulamaulama di Masjid Al Haram.

Sebagian penulis menyebut-kan bahwa Syeikh Ahmad Khatib tidak pernah lagi menginjakkan kaki di kampung halamannya setelah perjalanan haji yang pertama tersebut. Namun catatan pribadi Syeikh Ahmad Khatib menyebutkan bahwa atas permintaan dari ibunya yang rindu kepadanya, maka Ahmad Khatib kembali ke kampung halamannya pada tahun 1292 H. Kepulangan Ahmad Khatib dari Makkah setelah bermukim 5 tahun di sana sebe-narnya adalah kepulangan layaknya orang yang telah selesai dalam melaksanakan tugasnya alias pulang habis. Meskipun begitu kerinduan Ahmad Khatib tetap terpendam untuk suatu ketika kembali ke Makkah melanjutkan fase kedua dari pengembaraannya menuntut ilmu di Makkah. (Khatib: 8)

Setelah lebih dari satu tahun di Indonesia Ahmad Khatib men-dapat kesempatan untuk berangkat ke Makkah untuk kedua kalinya. Semangat menuntut ilmunya kembali bergelora meskipun selama di Indonesia beliau juga sempat menuntut ilmu kepada Tuanku Nan Mudo dan menuntaskan membaca buku Matn alMinhaj, Tafsir Jalalain dalam lima juz.

\section{KEDUDUKAN KEILMUAN SYEIKH AHMAD KHATIB}

Ahmad

Khatib

al-

Minangkabawi adalah ulama besar yang pernah dilahirkan dari "rahim" Minangkabau. Benih yang bagus dan baik itu begitu mudahnya berkem-bang di tanah yang sangat dicintai oleh Utusan Allah yaitu tanah Makkah. Kebesaran Ahmad Khatib terlihat dalam skala ruang lingkup yang demikian luas.

Pengaruh luas Ahmad Khatib ditandai dengan posisinya yang prestisius dan penting sebagai syekh (guru besar) sekaligus khatib dan imam besar mazhab Syafii di Masjidil Haram. Jabatan tersebut mencakup kawasan wilayah Hijaz, sebuah kepercayaan yang sangat langka untuk orang nonArab. Semua literatur tentang Ahmad Khatib mencatat bahwa kedudukan ini beliau capai terkait dengan ketinggian dan kedalaman ilmunya di berbagai bidang, khususnya Ilmu Fiqh dan Hukum Islam, di samping ilmu-ilmu lain seperti Ilmu Falak, Ilmu Hisab, dan Tasawuf. Pengangkatan itu dilatarbelakangi kredibilitas dan kapabilitas keilmuannya. Dalam rentang waktu 9 tahun ia mampu menyelesaikan pembelajaranya dari ulama Makkah terkemuka saat itu, semisal Sayyid Zayn al-Dahlan, Syekh Bahr al-Syatta, dan Syekh Yahya alQabli. Snouck Hurgronje, penasehat pemerintah Kolonial Belanda yang sangat membenci Ahmad Khatib seperti dikutip Martin Van Bruinessenmengakui Ahmad Khatib sebagai "sangat alim untuk ukuran Melayu".

Dengan posisi pentingnya di Masjidil Haram itu, maka Ahmad Khatib termasuk tokoh sentral dunia Islam pada masanya. Ia menjadi bagian 
dari jaringan ulama Haramayn yang berperan penting dalam penyebaran gagasan-gagasan keilmuan dan pembaharuan ke seluruh dunia Islam. Karena itu, diskursus dunia Islam akhir abad 19 dan atau awal abad 20, harus mencantumkan nama besar putera Agam ini. Transmisi keilmuan dan pembaharuan terjadi lewat para jamaah haji, baik yang mukim hingga bertahun-tahun maupun yang hanya berguru beberapa waktu menjelang pulang ke tanah air. Bersama para murid ini, ulama-ulama besar itu termasuk Ahmad Khatib tentunya membentuk komu-nitas ilmiah kosmopolitan di Haramayn (Azra, 2007: 386-7). Murid-murid inilah yang kemudian menjadi transmitter utama tradisi intelektual keilmuan di dunia Islam.

Kebesaran Ahmad Khatib dalam skala internasional ini tidak hanya di Haramayn, tetapi melebar ke jazirah Arab bahkan lebih luas lagi. Ini terbukti ketika pemerintah Turki menganugerahinya gelar "Bey Tunis" semacam gelar "Doktor Honoris Causa" masa kini, yang lazimnya diberikan kepada bang-sawan Tunisia yang berjasa besar bagi pengembangan ilmu penge-tahuan (Tamar Djaja, 1965: 57). Pengaruh Ahmad Khatib juga sangat besar di kawasan Semenanjung Malaya (Malaysia dan Singapura). Salah seorang murid dan juga saudara sepupunya, Syekh Thahir Djalaluddin, seorang ulama ahli Falak yang ternama, merupakan ulama besar di Malaysia.

Kebesaran Ahmad Khatib juga dapat dilihat dari pengaruhnya pada skala Nasional. Sebagian besar ulama pembaharu di berbagai wilayah Indonesia pada awal abad 20 adalah murid Ahmad Khatib. Martin Van
Bruinessen (1995: 38) menye-butnya sebagai "bapak reformis Islam Indonesia”. Martin juga menjelaskan bahwa Ahmad Khatib adalah salah seorang ulama Nusan-tara di Makkah yang mengilhami gerakan agama di Indonesia dan mendidik banyak ulama yang kemudian berperan penting di Indonesia (1995: 52). Snouck Hurgronje mencatat, semua orang Indonesia yang naik haji ketika Ahmad Khatib hidup, pasti mengunjungi beliau. Karena itu menurut Burhanuddin Daya, dapat diterima bahwa pengaruh putera Minangkabau ini sangat besar dan penting bagi kebangkitan umat Islam Indonesia pada abad ke-20 (Daya, 1990: 63).

Hal yang menarik dari pengaruh Ahmad Khatib di Nusantara adalah, bahwa meski ia sendiri secara pribadi memegang teguh dan kokoh pada pendiriannya, bahkan keras atas beberapa persoalan keagamaan seperti soal tarekat - tetapi muridmuridnya ternyata memiliki pendapat yang berbeda dengan Ahmad Khatib sendiri. Menurut Burhanuddin Daya, ia telah melahirkan ulama-ulama penggerak kegiatan berijtihad, baik yang mengobarkan gerakan pembaharuan pemikiran Islam, maupun ulama-ulama yang menentang pembaharuan. Menurutnya, Ahmad Khatib tidak menanamkan taklid kepada para muridnya. Mereka diberi kebebasan dan bahkan dianjurkan mempelajari karya-karya Abduh dan al-Afghani -icon reformer dunia Islamagar bisa membantah pendapat beliau (Daya, 1990: 58-9, 63-4).

Dengan begitu maka sangat wajar jika kemudian murid-muridnya memiliki dan mengembangkan corak pembaharuan keagamaan yang 
beragam. Literatur-literatur tentang Ahmad Khatib mencatat sebagian kecil dari begitu banyak muridnya yang menjadi pelopor dan tokoh pembaharu di Nusantara. Selain ulama Minangkabau, terdapat nama-nama besar pendiri dan tokoh ormas Islam di tanah air. KH. Ahmad Dahlan, pendiri Muhammadiyah, adalah murid beliau yang diutus belajar ketika terjadi polemik tentang arah kiblat pada Masjid Agung Kraton Yogyakarta. Muridnya yang lain, KH. Hasyim Asy'ari -kakek Gus Dur- berguru antara tahun 1893-1900. Haji Abdul Halim Majalengka, pelopor pembaharu Islam Jawa Barat, pendiri Hayatul Qulub, juga murid Ahmad Khatib (Daya, 1990: 77-8). Syekh Abdul Hamid, ulama masyhur Mandailing belajar 10 tahun pada Ahmad Khatib (Bruinessen, 1996: 143). Murid-murid termasyhur lainnya di luar Minangkabau adalah Syekh Hasan Maksum (Mufti Kesultanan Perak), Syeikh Muhammad Nur (Mufti Kerajaan Langkat), Syekh Abdullah Saleh (Mufti Kesultanan Johor), Syekh Muhammad Zain (Mufti Kerajaan Perak), Haji Muhammad Nur Islamil (Kadi Kerajaan Langkat), Syekh Mustafa Purba, (pendiri Pesantren Syafi'iyah Purba Baru), Syaikh 'Abdurrahman Shiddiq bin Muhammad 'Afif Al Banjari (Mufti Kerajaan Indragiri), serta Haji Muhammad Basyuni Imran (Maharaja Imam/ Hakim dan Kepala Urusan Agama Kerajaan Sambas). Dari sini terlihat kebesaran Syeikh Ahmad Khatib ketika banyak Raja dan Sultan di Nusantara dan Melayu yang meminta fatwa kepada beliau melalui surat menyurat (ICSB: 17).
Dalam konteks Sumatera Barat atau Minangkabau, peran luar biasa Ahmad Khatib dalam pengembangan keilmuan dan pembaharuan tampak jelas. Sama dengan sebelumnya, pada skala lokal pun perbedaan paham keagamaan para murid ulama besar ini menjadi fenomenal. Banyak peneliti menyebut Ahmad Khatib adalah tokoh utama pencetus gerakan pembaharuan keagamaan di Minangkabau. Menurut Murni Djamal (2002: 14), Ahmad Khatib berhasil menyebarkan pikiran dan ajarannya ke Indonesia dan Malaya, khususnya Minangkabau karena memang sejumlah besar muridnya berasal dari sini. Ia sukses membekali muridnya dari Minangkabau dengan dua pelajaran penting, yakni pertama, membuka pintu menjalankan ijtihad, dan kedua, keharusan memurnikan agama dari praktek-praktek keagamaan yang tidak benar.

Murid-murid Ahmad Khatib di Minangkabau terdiri dari Kaum Tuo dan Kaum Mudo. Menurut Burhanuddin Daya, di sinilah letak kebesaran beliau. Menurutnya, hampir semua ulama dan pemimpin terkemuka Islam yang lahir di kurun waktu seperempat abad menjelang dekade terakhir abad XX, menjadi asuhan beliau. Mereka semua menjadi aktifis dan penggerak-penggerak Islam (Daya, 1990: 59-63). Murid-muridnya dari kalangan Kaum Mudo, tercatat antara lain Muhammad Thaib Umar, Abdullah Ahmad, Abdul Karim Amrullah, Muhammad Djamil Djambek, Daud Rasyidi, Abdul Latif Syakur, Abbas Abdullah, Ibrahim Musa Parabek, Haji Agus Salim, dan Sutan Darap Pariaman (Daya, 1990: 77 dan Steenbrink, 1986:37). Sedang dari kalangan Kaum 
Tuo, tercatat ulama-ulama besar Khatib Ali, Sulaiman Ar-Rasuli, dan Muhammad Jamil Jaho. Semua syeikhsyeikh ini, baik Kaum Mudo maupun Kaum Tuo, nama-nama mereka tidak asing lagi dalam sejarah pembaharuan di Sumatera Barat.

Alwi Shihab menyebut Ahmad Khatib adalah "mentor" para pembaru di Minangkabau, baik tradisionalis maupun modernis. Meski ia dikenal sebagai pengkritik keras praktek sufi dan tarekat serta beberapa adat istiadat Minangkabau, tetapi bukan berarti ia menentangnya begitu saja. Menurut Azra (2007: 380), ulama-ulama seperti Ahmad Khatib (dan juga al-Bantani) ini pada permukaan kelihatannya sangat anti sufisme, namun dengan pengamatan yang teliti atas karyakaryanya terlihat bahwa yang mereka tentang adalah sufisme yang berlebihan (excessive) dan lari dari kenyataan (escapist). Di sisi lain, mereka menerima sufisme yang lebih puritan, yang kukuh berorientasi pada rekonstruksi sosio-moral masyarakat Muslim. Djamal (2002: 11) menyebut Ahmad Khatib sebagai seorang Sufi di samping sebagai Imam Mazhab.

Dalam kapasitasnya sebagai ulama besar, guru para ulama tokoh pembaharu Sumatera Barat, tentunya melihat Ahmad Khatib tidak dengan pandangan sempit. Sangat arif kiranya jika Martin Van Bruinessen menyebut bahwa peranan Ahmad Khatib di Mekah lebih luas dari polemiknya dengan kaum adat dan tarekat. Adalah salah -kata Martin- menganggap Ahmad Khatib hanya sebagai pemberontak tradisi; ia bahkan pun mendalaminya. Di antara muridnya ada yang reformis dan tradisionalis, bahkan menjadi syekh tarekat. Menurut Martin, dua kitab Ahmad Khatib masih dipakai di beberapa pesantren. Melihat keluasan ilmu dan semangat pembaharuan yang ditularkannya kepada para muridnya, bisa jadi polemik yang melibatkannya itu justru menjadi pembuka cakrawala berfikir, membangun semangat menggali keilmuan, dan menghargai perbedaan pendapat. Dalam budaya Minangkabau dikenal bahwa silang selisih lebih sebagai enerji positif. "Basilang kayu di tungku, mangkonyo api iduik", begitu kata pepatah.

Karya-karya Syeikh Ahmad Khatib ditulis dalam bahasa Arab dan bahasa Melayu. Berbagai sumber menyebutkan karya beliau sebagai berikut:

Karya berbahasa Arab:

- Hasyiyah An Nafahat 'ala Syarhil Waraqat lil Mahalli

- Al Jawahirun Naqiyyah fil A'malil Jaibiyyah

- Ad Da'il Masmu' 'ala Man Yuwarritsul Ikhwah wa Auladil Akhwan Ma'a Wujudil Ushul wal Furu'

- Raudhatul Hussab

- Mu'inul Jaiz fi Tahqiq Ma'nal Jaiz

- As Suyuf wal Khanajir 'ala Riqab Man Yad'u lil Kafir

- Al Qaulul Mufid 'ala Mathla'is Sa'id

- An Natijah Al Mardhiyyah fi Tahqiqis Sanah Asy Syamsiyyah wal Qamariyyah

- Ad Durratul Bahiyyah fi Kaifiyah Zakati Azd Dzurratil Habasyiyyah

- Fathul Khabir fi Basmalatit Tafsir

- Al 'Umad fi Man'il Qashr fi Masafah Jiddah

- Kasyfur Ran fi Hukmi Wadh'il Yad Ma'a Tathawuliz Zaman 
- Hallul 'Uqdah fi Tashhihil 'Umdah

- Izhhar Zaghalil Kadzibin fi Tasyabbuhihim bish Shadiqin

- Kasyful 'Ain fi Istiqlal Kulli Man Qawal Jabhah wal 'Ain

- As Saifu Al Battar fi Mahq Kalimati Ba'dhil Aghrar

- Al Mawa'izh Al Hasanah Liman Yarghab minal 'Amal Ahsanah

- Raf'ul Ilbas 'an Hukmil Anwat Al Muta'amil Biha Bainan Nas

- Iqna'un Nufus bi Ilhaqil Anwat bi 'Amalatil Fulus

- Tanbihul Ghafil bi Suluk Thariqatil Awail fima Yata'allaq bi Thariqah An Naqsyabandiyyah

- Al Qaulul Mushaddaq bi Ilhaqil Walad bil Muthlaq

- Tanbihul Anam fir Radd 'ala Risalah Kaffil 'Awwam, sebuah kitab bantahan untuk risalah Kafful 'Awwam fi Khaudh fi Syirkatil Islam karya Ustadz Muhammad Hasyim bin Asy'ari yang melarang kaum muslimin untuk nimbrung di Sarekat Islam (SI)

- Hasyiyah Fathul Jawwad dalam 5 jilid

- Fatawa Al Khathib 'ala Ma Warada 'Alaih minal Asilah

- Al Qaulul Hashif fi Tarjamah Ahmad Khathib bin 'Abdil Lathif

- Adapun karya beliau yang berbahasa Melayu adalah:

- Mu'allimul Hussab fi 'Ilmil Hisab

- Ar Riyadh Al Wardiyyah fi [Ushulit Tauhid wa] Al Fiqh Asy Syafi'i

- Al Manhajul Masyru' fil Mawarits

- Dhaus Siraj Pada Menyatakan Cerita Isra' dan Mi'raj

- Shulhul Jama'atain fi Jawaz Ta'addudil Jumu'atain

- Al Jawahir Al Faridah fil Ajwibah Al Mufidah
- Fathul Mubin Liman Salaka Thariqil Washilin

- Al Aqwal Al Wadhihat fi Hukm Man 'Alaih Qadhaish Shalawat

- Husnud Difa' fin Nahy 'anil Ibtida'

- Ash Sharim Al Mufri li Wasawis Kulli Kadzib Muftari

- Maslakur Raghibin fi Thariqah Sayyidil Mursalin

- Izhhar Zughalil Kadzibin

- Al Ayat Al Bayyinat fi Raf'il Khurafat

- Al Jawi fin Nahw

- Sulamun Nahw

- Al Khuthathul Mardhiyyah fi Hukm Talaffuzh bin Niyyah

- Asy Syumus Al Lami'ah fir Rad 'ala Ahlil Maratib As Sab'ah

- Sallul Hussam li Qath'i Thuruf Tanbihil Anam

- Al Bahjah fil A'malil Jaibiyyah

- Irsyadul Hayara fi Izalah Syubahin Nashara

- Fatawa Al Khathib dalam versi bahasa Melayu

\section{SEMANGAT MENUNTUT ILMU: MENEMUKAN WARISAN SYEIKH AHMAD KHATIB}

Semangat menuntut ilmu ke tanah kelahiran Islam sangatlah tinggi dan telah dimulai sejak abad ke-17 hingga akhir abad ke-19. Negeri yang menjadi tujuan para penuntut ilmu dari Melayu-Indonesia adalah Haramain (Makkah-Madinah). Azra menyebutnya telah terjadi hubungan yang intens antara penuntut ilmu dari Indonesia dengan ulama di Haramain dan bahkan al-Azhar Kairo dalam perjalanan menuntut ilmu (rihlah ilmiah li thalab al-'ilm). (Azra: Abaza, xvi).

Pada Pertengahan abad ke-19 baru mulai muncul gelombang para penuntut ilmu ke al-Azhar. Hal utama 
yang mendasari gelombang ini pada awalnya adalah semata-mata keinginan untuk menuntut ilmu agama (al-‘ulum al-syar'iyyah). Namun sejalan dengan timbulnya kesadaran masyarakat dunia Islam tentang pentingnya kemerdekaan dari belenggu imperialisme, maka gerakan kemerdekaan menjadi dorongan lain untuk menggali ilmu yang dapat menggerakkan semangat kemerdekaan dan anti penjajahan asing. Azra menukilkan ungkapan seorang mahasiswa Jawa "di Makkah kita hanya belajar agama; tetapi di Kairo kita juga (mempelajari) politik". (Azra: xix).

Dampak gerakan Pan Islamisme di Mesir ke negara-negara lainnya seperti Indonesia. Terutama melalui gagasan al-Afghani (melalui jurnal alManar) dengan terbentuknya alJam'iyyah al-Khairiyah al-Thullabiyah al-Jawwiyah yang menerbitkan Seruan al-Azhar dan Pilihan Timur yang kemudian dilarang oleh kolonial Belanda beredar di Indonesia. (Azra: xxii)

Pada masa semangat menuntut ilmu ke sumber wahyu yang sedang tumbuh inilah Syeikh Ahmad Khatib bertolak ke Makkah untuk melaksanakan ibadah haji dan sekaligus melakukan perjalanan ilmiah (al-rihlah al-ilmiah). Sebagaimana yang ditulis oleh Ahmad Khatib sendiri bahwa beliau adalah pencinta ilmuilmu agama. Oleh karena itu, menjadi seorang berilmu adalah cita-cita beliau sejak kecil hingga dewasa. Beliau mengungkapkan dalam sejarah hidupnya:

"diwaktu kecil aku sangat mencintai ilmu dan ulama. Kalau ada yang mengatakan kepadaku ketika itu, bahwa engkau insya Allah akan menjadi penguasa di negeri ini menggantikan pamanmu, maka aku akan marah besar dan langsung menyahuti dengan mengatakan bahwa insya Allah aku akan menjadi seorang Alim dan Syeikh dalam agama Islam..."

Ahmad Khatib menggambarkan kecintaannya kepada ilmu:

"Aku waktu itu sangat merindukan Makkah agar dapat kembali menuntut ilmu di sana. Aku tidak dapat merasakan ketenangan di negeri ini (ketika beliau berada di Padang) karena kerinduan yang memuncak kepada Makkah. Sehingga dalam tidur aku masih merasa sedang di Makkah dan ketika bangun baru tersadar bahwa aku masih di negeri itu (Padang). Aku kecewa dan sedih dengan kondisi ini. Oleh karena itu, aku mencoba menghibur diri dengan menaiki kuda sewaan keliling kota (Padang). Selain itu orang tuaku terlalu sibuk dengan perdagangan sehingga tidak punya waktu Dn keinginan untuk mengantarkanku kembali ke Makkah. Namun aku tetap berdoa kepada Allah agar dibukakan pintu menuntut ilmu kembali di Makkah. Aku yakin Allah akan mengabulkan doaku, lalu tanpa ku sadari Dia memperjalankan hambaNya Syeikh Utsman Syatta, guruku. Dalam perjalanan panjangnya guruku tersebut berkesempatan 
singgah di Padang dan menginap di rumah Jaksa Padang yang merupakan pamanku sendiri. Beliau menanyakan tentang diriku dan ingin bertemu denganku. Dengan takdir Allah akupun bertemu dengan Syeikh Utsman Syatta. Aku mengutarakan kepada beliau kerinduanku untuk menuntut ilmu di Makkah, tapi orang tua dan keluarga besarku melarang. Aku berharap guruku dapat menjelaskan kepada keluargaku tentang hal ini. Maka ketika diadakan pertemuan keluarga yang dihadiri oleh Syeikh Utsman Syatta, beliau mengatakan dalam pertemuan tersebut "sudah banyak dari anggota keluarga ini yang menjadi orang penting dalam pemerintahan Belanda, dan semua itu untuk urusan duniawi dan berkaitan dengan orang Nasrani, maka saya menyarankan agar Ahmad diizinkan untuk mendalami ilmu agama di Makkah. Hanya dengan ilmu agamalah kita akan selamat di dunia dan akhirat. Allah mencintai para ulama. Siapkanlah Ahmad untuk kehidupan akhirat kelak dan anak-anak kalian yang lainnya untuk kehidupan dunia. Anak ini telah mendapatkan pendidikan dasarnya di Makkah dan menguasai bahasa Arab, semua itu sudah merupakan setengah dari ilmu pengetahuan. Maka untuk melengkapi yang setengah lagi izinkan dia berangkat ke Makkah untuk melanjutkan perjalanan keilmuannya. Kami melihat kecerdasan, dan kehausannya kepada ilmu, dan dia akan menjadi cahaya bagi keluarga dan masyarakat kalian..." (Khatib: 9-11)

Semangat menuntut ilmu yang tinggi ini juga digambarkan oleh Syeikh Umar Abdul Jabbar:

...beliau adalah santri teladan dalam semangat, kesungguhan, dan keteku-nan dalam menuntut ilmu serta bermudzakarah malam dan siang dalam berbagai disiplin ilmu. Karena semangat dan ketekunannya dalam menuntut ilmu-ilmu umum seperti matematika, aljabar, tehnik, arsitektur dan ilmu-ilmu syariat, beliau dapat menulis buku dalam disiplin ilmu-ilmu itu dipelajari secara otodidak. (Jabbar: 38-39)

Syeikh Ahmad Khatib adalah pencinta ilmu dan ulama. Dengan bekal itu dan usaha yang gigih akhirnya beliau meraih ilmu dan sekaligus menjadi seorang ulama besar yang mumpuni. Beliau tidak saja menguasai ilmu agama tetapi juga ilmu yang berkaitan dengan kehidupan dunia. Berbekal ilmu-ilmu itulah Syeikh Ahmad Khatib menjadi ensiklopedi ilmu yang berguna bagi masyarakat. Allah mengabulkan doa gurunya Syeikh Utsman Syatta yang mengatakan bahwa Ahmad Khatib akan menjadi cahaya bagi keluarga dan masyarakatnya. Cahaya merupakan petunjuk dalam memahami realitas dan kemudian memanfaatkannya. Cahaya 
yang diberikan oleh Ahmad Khatib tidak lain adalah ilmu dan ilmu itulah warisan berharga yang ditinggalkan oleh para Nabi dan ulama.

Dengan ilmu yang dimiliki Syeikh Ahmad Khatib, beliau menjadi magnet bagi seluruh kalangan di kala itu, terutama masyarakat Indonesia yang melaksanakan ibadah haji. Semua orang mengambil ilmu yang dibutuhkan dari beliau, mulai dari ilmu fikih, tasauf, falak, hitung dan lain sebagainya.

\section{REFLEKSI UNTUK SUMATERA BARAT KE DEPAN}

Semangat menuntut ilmu ke Timur Tengah yang diwarisi oleh generasi terdahulu tidak pernah pudar dalam diri para pemuda Indonesia. Bahkan semangat itu menjadi luar biasa pada dekade terakhir. Hal itu disebabkan oleh beberapa faktor, pertama, sulitnya mencari lembaga pendidikan tinggi Islam di Indonesia yang fokus mengajarkan ilmu syariat. Kedua, prestise lembaga pendidikan Islam di Timur Tengah masih berada di atas lembaga pendidikan Islam di Indonesia. Ketiga, masih hidup keyakinan bahwa menjadi seorang yang berilmu agama yang mumpuni tempatnya di Timur Tengah. keempat, mahalnya pendidikan di dalam negeri dibandingkan dengan di Timur Tengah apalagi ada banyak jalan untuk mendapatkan beasiswa.

Berangkat dari semangat itu maka sampai hari ini ada ribuan mahasiswa Indonesia di Timur Tengah. Mulai dari Maroko sampai ke anak benua India; dari jenjang pendidikan strata satu sampai strata tiga; dari yang diutus oleh negara sampai dengan kemauan sendiri; dari yang berbeasiswa sampai yang terjun bebas. Gelombang penuntut ilmu ke Timur Tengah beradu gigih dengan upaya Pemerintah yang menyiapkan berbagai kebijakan dan fasilitas pengiriman mahasiswa tugas belajar ke Eropah dan Amerika. Jika para penuntut ilmu ke Timur Tengah di dominasi oleh mereka yang berangkat dengan inisiatif dan biaya sendiri, maka pelajar yang berangkat ke Barat untuk melakukan studi Islam mendapatkan biaya penuh baik dari Pemerintah Indonesia maupun negara tujuan. Hampir dipastikan tidak ada yang belajar di sana dengan inisiatif dan biaya sendiri.

Pemerintah Provinsi Suma-tera Barat mulai memberikan perhatian yang cukup serius kepada pelajar di Timur Tengah dengan memberikan bantuan beasiswa dan membangun wisma mahasiswa. Di Kairo umpamanya telah berdiri Rumah Gadang untuk mahasiswa yang kuliah di sana. Bantuan itu bermula dari kunjungan Gubernur Gamawan Fauzi ke Kairo bulan September 2007 untuk melihat lokasi pembangunan wisma tersebut. Pada bulan Juli 2009 berdirilah wisma mahasiswa yang diresmikan oleh Ketua DPRD Sumatera Barat waktu itu H. Leonardy Harmainy. Sampai hari ini wisma empat lantai itu telah digunakan oleh mahasiswa sebagai tempat tinggal maupun kegiatan ilmiah-sosial lainnya.

Sebagian dari mahasiswa yang menggunakan fasilitas wisma itu telah menamatkan pendidikannya di Kairo dan mereka telah berada di Indonesia. Sebagian ada yang kembali ke Sumatera Barat dan sebagian besar tersebar di kota-kota besar Indonesia dan sebagian lagi menetap di Malaysia dan Brunei. Kondisi ini seperti 
meneruskan tradisi lama mahasiswa Minangkabau yang telah selesai melaksanakan pendidikan di al-Azhar Kairo; ada yang pulang kampung tetapi lebih banyak yang melanjutkan rantaunya untuk mencari kehidupan yang dianggap lebih tepat. Tidak heran banyak dari mahasiswa Minangkabau alumni al-Azhar yang menetap di Belanda, Jerman atau negara-negara lainnya.

Pada dekade terakhir para alumni al-Azhar dari Minangkabau banyak yang kembali ke Indonesia dan melakoni aktifitas sebagai penyelenggara biro perjalanan haji dan umrah. Profesi ini tentu bermanfaat membantu umat Islam dalam melaksanakan ibadah haji dan umrah, namun ada pekerjaan lain yang terabaikan yaitu sebagai guru bagi masyarakat di mana mereka berasal.

Tidak sedikit pula yang menjadi politisi yang berjuang dengan pendekatan politik. Hal ini tentu juga berguna bagi kebijakan politik yang berpihak kepada kebaikan Islam dan umatnya. Tetapi juga tidak bisa dipungkiri, diakui atau tidak politik praktis telah membuat umat terkotakkotak dalam bingkai partai politik. Cukup sulit ulama dari partai politik tertentu diterima apa adanya oleh komunitas politik lain dan sebaliknya. Label sebagai "orang politik" yang selalu punya ambisi dan misi kepentingan kekuasaan sulit dihilangkan dari asumsi masyarakat. Karena politik sesungguhnya adalah persaingan untuk meraih kekuasaan dengan adagium dan sifatnya yang khas.

Sebagian alumni ada yang menjadi ustadz dan pengajar di pesantren dan sekolah agama. Hanya sebagian kecil dari alumni al-Azhar di Sumatera Barat yang menjadi guru dan dosen institusi negeri (SD sampai Perguruan Tinggi). Ada beberapa faktor yang menjadi kendala alumni alAzhar untuk menjadi Guru dan Dosen di lembaga Pemerintah. Faktor pertama adalah informasi yang terbatas seputar proses seleksi calon pegawai negeri sipil atau dosen. Kedua, kalaupun punya informasi biasanya terbentur masalah umur. Ketiga, jikapun tidak bermasalah dalam masalah umur, kendala lain adalah materi ujian yang tidak pernah atau jarang ditemui selama masa pendidikan di Timur Tengah, semisal Bahasa Indonesia, Kewarganegaraan, psikotes dan lain sebagainya.

Langkah Pemerintah Provinsi menyediakan wisma mahasiswa dan pemberian beasiswa untuk mahasiswa alumni al-Azhar perlu mendapatkan apresiasi dan penghargaan yang tinggi. Namun sesuai dengan konsep link and match, langkah awal itu perlu disertai dengan langkah berikutnya yang lebih efisien dan efektif. Bagaimanapun masyarakat Sumatera Barat sadar betapa para alumni tersebut dibutuhkan untuk membangun Sumatera Barat yang dipagari oleh filosofi ABS-SBK. Komunitas alumni yang dibutuhkan oleh daerah itu, sejak dahulu sampai sekarang memiliki berbagai kekurangan dalam upaya aktualisasi diri dan aplikasi kompetensi seperti yang disebutkan di atas. Tentu harus ada upaya dari berbagai pihak di Sumatera Barat mengembalikan semacam "permata yang hilang" agar dapat mengabdikan diri dengan optimal di Sumatera Barat. 
Banyaknya alumni yang "tercecer" di berbagai negara dan daerah dengan profesi yang beragam menandakan bahwa ada sesuatu yang kurang tepat dalam memahami dan memberdayakan alumni Timur Tengah. Persoalan ini lebih menarik lagi apabila ditinjau dari latar belakang dan proses keberangkatan angkatan muda Sumatera Barat menuntut ilmu di Timur Tengah. Mereka yang "diutus" untuk menimba ilmu di Timur Tengah dapat dipastikan dilepas dengan untaian doa agar berhasil dalam misi suci tersebut. Di ujung doa terselip harapan "semoga setelah tamat nanti dapat kembali dan membangun kampung halaman di bidang pengajaran ilmu, membangun agama dan menegakkan akhlak mulia". Tidak jarang doa itu diiringi oleh berbagai bantuan baik berbentuk materi maupun moril. Termasuk dalam hal ini pemberian beasiswa, bantuan dana dan pembangunan wisma mahasiswa oleh Pemerintah dan DPRD. Hanya saja upaya-upaya itu seperti banyak yang "hilang dihembus angin", atau seperti "mamaga karambia condong" baik condong ke daerah lain maupun condong ke profesi yang jauh dari proses pendidikan, dakwah dan penanaman akhlak karimah.

Sebagai bandingan, bisa dikatakan seluruh mahasiswa dari Malaysia dan Brunei setamat pendidikan di Timur Tengah mendapatkan "tugas" selanjutnya dari negara sesuai dengan kapasitas mereka masing-masing. Di sini terlihat terlaksananya konsep link and match dalam proses pendidikan dan pengabdian mahasiswa yang memang seluruhnya dibiayai oleh kerajaan dan negeri masing-masing. Mahasiswa alumni itu tidak seperti orang asing di negerinya sendiri. Mereka sudah memiliki gambaran apa, bagaimana dan dimana mereka akan berkiprah. Mereka seperti terikat dengan niat semula "menuntut ilmu dan mengabdikan diri untuk negeri dan masyarakatnya" dan segala sesuatu berjalan seperti telah memiliki Standard Operational Procedure (SOP).

\section{PENUTUP}

Kehidupan dan perjalanan keilmuan Syeikh Ahmad Khatib merupakan refleksi dari kecintaan beliau kepada ilmu dan ulama. Semangat itu masih diwarisi oleh generasi berikutnya sampai hari ini. Sebagai buktinya, para penuntut ilmu yang bercita-cita untuk menyauk ilmu di Timur Tengah semakin banyak. Di ranah Minangkabau sendiri, semangat untuk merantau ke Timur Tengah menuntut ilmu semakin membara. Setiap tahun ratusan calon mahasiswa mengikuti seleksi untuk menjadi mahasiswa di beberapa universitas ternama di Timur Tengah.

Di tengah berjalannya proses itu, sebagian dari pengembara ilmu itu telah kembali ke ranah Minangkabau. Tetapi sebagian besar mereka berada di luar Minangkabau, baik itu sebagai guru agama, pengajar, pegawai maupun sebagai pelaku bisnis. Kondisi ini tidak terlepas dari situasi sosial di kampung halaman mereka untuk mengabdi setelah sekian lama menuntut ilmu di Timur Tengah.

Masyarakat Sumatera Barat sangat berharap kehadiran mereka untuk mengimplementasikan ilmu yang telah mereka tuntut. Adanya kendalakendala terkait dengan itu merupakan 
lahan yang harus digarap oleh seluruh komponen di Sumatera Barat, agar pinang pulang ka tampuaknyo, siriah pulang ka gagangnyo. Tanpa usaha yang serius dari hulu sampai hilir,

\section{REFERENSI}

Abaza, Mona, Pendidikan Islam dan Pergeseran Orientasi; Studi Kasus Alumni al-Azhar, LP3ES Jakarta: 1999

Abduljabbar, Umar, Siyar wa Tarajim Ba'dhi 'Ulamaina fil Qarn Ar Rabi' 'Asyar lil Hijrah. KSA: Tihamah, 1403 $\mathrm{H}$.

Azra, Azyumardi, Jaringan Ulama Timur Tengah dan Kepulauan Nusantara abad XVII dan XVIII. Jakarta: Penada Media, 2007.

Dahlan, Dadang A. Cahaya dan Perajut Persatuan Waliullah Ahmad Khatib Al Minangkabawy. Yogyakarta: Adicita Karya Nusa, 2007.

Daya, Burhanuddin, Gerakan Pembaharuan Pemikiran Islam, Yogyakarta: Tiara Wacana Yogya, 1990.

Djamal, Murni, Haji Abdul Karim Amrullah Pengaruhnya dalam mengaplikasikan konsep link and match hampir dipastikan langkah kedepan hanya seperti mamaga karambia condong.

gerakan Pembaharuan Islam di Minangkabau Pada Awal Abad ke-20 Leiden - Jakarta 2002

Djaya, Tamar, Pustaka Indonesia: riwajat hidup orang-orang besar tanah air, Bulan Bintang, 1965.

Martin van Bruinessen, Martin Van Bruinessen, Tarekat Naqsyabandiyah di Indonesia, Bandung : Mizan, 1992-1995.

al-Minangkabawi, Syeikh Ahmad Khatib, al-Qaul al-Nahif $f i$ Tarjamat Tarikh Hayati alSyaikh Ahmad ibn al-Khatib al-Minangkabawi. t.t, t.p.

Riwayat Hidup dan Perjuangan 20 Ulama Besar Sumatera Barat, Penerbit Islamic Center Sumatera Barat, 1981.

Steenbrink, Dr. Karel A. Beberapa Aspek Tentang Islam di Indonesia Abad Ke-19. Jakarta: Bulan Bintang, 1988 